\title{
Isotopic variations of meltwater from ice by isotopic exchange between liquid water and ice
}

\section{Paper}

Cite this article: Ham J-Y, Hur SD, Lee WS, Han Y, Jung H, Lee J (2019). Isotopic variations of meltwater from ice by isotopic exchange between liquid water and ice. Journal of Glaciology 65(254), 1035-1043. https://doi.org/ 10.1017/jog.2019.75

Received: 28 December 2018

Revised: 19 September 2019

Accepted: 19 September 2019

First published online: 5 November 2019

Key words:

Ice chemistry; ice core; meltwater chemistry

Author for correspondence:

Jeonghoon Lee,

E-mail: jeonghoon.d.lee@gmail.com (c) The Author(s) 2019. This is an Open Access article, distributed under the terms of the Creative Commons Attribution-

NonCommercial-NoDerivatives licence (http:// creativecommons.org/licenses/by-nc-nd/4.0/), which permits non-commercial re-use, distribution, and reproduction in any medium, provided the original work is unaltered and is properly cited. The written permission of Cambridge University Press must be obtained for commercial re-use or in order to create a derivative work.
Ji-Young Ham¹, Soon Do Hur², Won Sang Lee ${ }^{2}$, Yeongcheol Han², Hyejung Jung ${ }^{1}$ and Jeonghoon Lee $^{1}$ (D)

${ }^{1}$ Department of Science Education, Ewha Womans University, Seoul 120-750, Korea and ${ }^{2}$ Korea Polar Research Institute, Incheon 406-840, Korea

\begin{abstract}
Predicting the isotopic modification of ice by melting processes is important for improving the accuracy in paleoclimate reconstruction. To this end, we present results from cold room laboratory observations of changes in the isotopic ratio $\left(\mathrm{D} / \mathrm{H}\right.$ and $\left.{ }^{18} \mathrm{O} /{ }^{16} \mathrm{O}\right)$ of ice cubes by isotopic exchange between liquid water and ice in nearly isothermal conditions. A 1-D model was fit to the isotopic results by adjusting the values of two parameters, the isotopic exchange rate constant $\left(k_{\mathrm{r}}\right)$ and the fraction of ice participating in the exchange $(f)$. We found that the rate constant for hydrogen isotopic exchange between liquid water and ice may be greater (up to $40 \%$ ) than that for the oxygen isotopic exchange. The range of the rate constant obtained from four melt experiments is from 0.21 to $0.82 \mathrm{~h}^{-1}$. The model results also suggest that $f$ decreases with the increasing wetness of the ice. This is because with increasing water saturation in ice, water may be present only in the small pores or some of the water that was exchanged with ice may be bypassed, decreasing the effective surface area over which the isotopic exchange can occur. The relationship between the two water isotopes $\left(\delta^{18} \mathrm{O}\right.$ vs $\left.\delta \mathrm{D}\right)$ was observed and modeled and the slope was $<8$, which is significantly different from the slope of the meteoric waterline. We note that these slopes were obtained without considering the sublimation process.
\end{abstract}

\section{Introduction}

Stable water isotopes of oxygen and hydrogen of snow/firn and ice from glaciated areas have been used for paleoclimate studies (Thompson and others, 1998; Masson-Delmotte and others, 2008; Hou and others, 2013). These studies entail that the isotopic compositions of precipitation track the surface temperature, that the isotopic compositions are preserved sequentially in a snow or ice profile, and that the modifications of the isotopic composition by vapor and water movement in a snowpack and ice are insignificant (Masson-Delmotte and others, 2008; Steen-Larsen and others, 2011). Only a few studies have examined how the isotopic composition of glacier snow and firn is changed by water or vapor flow (Taylor and others, 2001; Earman and others, 2006). The process by which snow is transformed into firn smooths out the variations in the profile of the isotopic composition as a function of the depth. Visible melt layers in ice cores indicate the presence of surface-generated water percolating through the snowpack, firn and ice (Koerner, 1997; Pohjola and others, 2002; Moran and Marshall, 2009; Moran and others, 2011). The magnitude of the possible consequences of these processes, such as enrichment of isotopic values of snow/firn/ice by percolating water, must be determined and the accuracy of the use of stable water isotopes in the ice cores as a proxy for past temperature should be assessed.

The effect of meltwater infiltration can be: (1) a reduction of seasonal isotopic signals and the elution of chemical species; (2) an isotopic enrichment of snowpack, firn and ice by the subsequent percolation of meltwater through recrystallization; and (3) an introduction of time gaps. Meltwater modification of seasonal isotopic signals has been reported by some studies (Taylor and others, 2001; Goto-Azuma and others, 2002; Moore and others, 2005; Zhou and others, 2008a; Lee and others, 2008a, 2008b, 2010a, 2015a, 2015b). Meltwater alterations of seasonal isotopic signals have traditionally been minimized by drilling ice cores in regions that experience little or no summertime melt, such as central Greenland and interior regions of Antarctica (Moran and others, 2011). Recently, studies conducted on past sea ice extension or environmental studies based on ice core records in coastal areas that experience occasional periods of summertime melt have led to a better understanding of meltwater effects on the isotopic ratio of snow, firn and ice (Kaczmarska and others, 2006; Moran and others, 2011).

To predict the isotopic modification of meltwater from ice, we used a 1-D model developed by Feng and others (2002) and used by Lee and others (2009) and Lee and others (2010a). To simulate the isotopic variations of ice by melting process, the model requires key parameters, the isotopic exchange rate constant between the ice and liquid water for oxygen and hydrogen (how fast the isotopic reaction reaches the isotopic equilibrium) and the amount of ice (or surface area) involved in the isotopic exchange. These parameters can only be tuned by controlled melting experiments, in which other physical and chemical parameters can be measured and their variations need to be controlled. In ice-melt systems, there are few works that 
quantitatively explain the isotopic variations of meltwater. In this paper, we first report on four ice-melt experiments conducted to estimate the rate constant of ice-water isotopic exchange by melting ice columns of various heights using different melt rates and measurements of the meltwater isotopic compositions for both hydrogen and oxygen. The isotopic results were compared to the model calculation results and the model parameters were adjusted to obtain the best fit. Then, the isotopic rate constant and the amount of ice involved in the reaction were calculated from the fit parameters.

\section{Methods}

\subsection{Melt experiments}

We made four experiments where we varied the percolation velocity. These experiments were conducted in a $-1^{\circ} \mathrm{C}$ cold room at Ewha Womans University in order to eliminate additional melt by air temperature (Fig. 1). For the experiment, we used a Plexiglas column $(90 \mathrm{~cm}$ high with an internal diameter of $12.5 \mathrm{~cm}$ ) that was placed on top of a perforated disk and funnel. The column was filled with ice cubes (each cube had the dimension of $3 \mathrm{~cm} \times 3 \mathrm{~cm} \times 3 \mathrm{~cm}=27 \mathrm{~cm}^{3}$ ) previously prepared using distilled water and was stored in a freezer for isotopic homogeneity. The bulk density of the ice was determined by measuring the volume inside the column and weight of the ice cubes in the column between 1 and $2 \mathrm{~kg}$. It was assumed that the isotopic compositions of ice are homogeneous for the ice cubes used in the experiment.

For each experiment (four cases), we used an infrared heat lamp $(50$ or $75 \mathrm{~W})$ to melt the ice at the top of a column. The lamp was suspended in the Plexiglas column and moved down to maintain a fixed distance between the ice surface and the lamp. The ice in the column was melted at a relatively constant rate for constant specific discharge at the bottom of the column. The Plexiglas column and tubes were wrapped in insulation to prevent meltwater from freezing inside the column and tubes. The melt rate was controlled by both the power of the used lamp and by the distance between the lamp and the ice surface. Meltwater arriving at the base of the column flowed through the perforated disk, into the funnel and to a rotating disk loaded with low-density polyethylene bottles through the tube. Meltwater was collected every 5-10 min after the first meltwater sample, depending on the melt rate and the height of the ice. We can determine (1) the mass of the recovered meltwater as a fraction of the total mass of the initial ice, (2) the mean flow rate at a given time, (3) the volume of meltwater as a function of time and (4) the time at which the first meltwater arrived at the end of the tube.

\subsection{Isotope analysis}

The samples were analyzed at the Korea Polar Research Institute and the isotopic compositions of hydrogen and oxygen were determined by a wavelength-scanned cavity ring-down spectroscopy (CRDS, L-2120-I, Picarro), which is a type of isotope ratio infrared spectroscopy. The $\mathrm{D} / \mathrm{H}$ and ${ }^{18} \mathrm{O} /{ }^{16} \mathrm{O}$ ratios were expressed in the $\delta$ notation as part per thousand differences relative to the Vienna Standard Mean Ocean Water (VSMOW). Memory effects between samples in the CRDS were corrected as suggested by Penna and others (2012) and the precisions of oxygen and hydrogen were 0.08 and $0.6 \%$, respectively $(1 \sigma)$.

\subsection{Numerical model}

We use the model developed by Taylor and others (2001) and Feng and others (2002) and investigated by Taylor and others
(2002), Lee and others (2009) and Lee and others (2010a). The model assumes a constant melt rate, and incorporates the advection of percolating water and ice-water isotopic exchange, but neglects the diffusion. Boundary conditions and numerical solutions are described in detail in Feng and others (2002). Assuming a homogeneous ice column being melted by a constant rate, the isotopic governing equations for the liquid water and ice are,

$$
\frac{\partial R_{\mathrm{liq}}}{\partial t}=-\frac{\partial R_{\mathrm{liq}}}{\partial z}+\psi \gamma\left(R_{\mathrm{ice}}-a_{\mathrm{eq}} R_{\mathrm{liq}}\right)
$$

$$
\frac{\partial R_{\text {ice }}}{\partial t}=\psi(1-\gamma)\left(a_{\mathrm{eq}} R_{\text {liq }}-R_{\text {ice }}\right)
$$

where $R_{\text {liq }}$ and $R_{\text {ice }}$ are the ${ }^{2} \mathrm{H} /{ }^{1} \mathrm{H}$ or ${ }^{18} \mathrm{O} /{ }^{16} \mathrm{O}$ ratio in the liquid water and ice, respectively. The dimensionless $z$ is the depth below the ice surface (normalized by the initial depth of the ice column) and $t$ is the time since onset of the melt (normalized by the time required for the meltwater to percolate through the initial depth of the ice column). The constant $a_{\mathrm{eq}}$ is the equilibrium fractionation factor for the isotopic exchange between ice and water at $0^{\circ} \mathrm{C}$. At equilibrium, the $\delta^{18} \mathrm{O}$ and $\delta \mathrm{D}$ of the water are expected to be 3.1 and $19.5 \%$ lower than those of the ice, respectively (O'Neil, 1968). The parameter $\gamma$ quantifies the fraction of the ice in the icewater isotopic exchange system,

$$
\gamma=\frac{b f}{a+b f}
$$

where $a$ and $b$ are the masses of liquid water and ice, respectively. The parameter $f$ denotes the fraction of ice involved in the isotopic reaction; $f$ will be dependent on the size and surface roughness of ice grains, the accessibility of the ice surface to the percolating water and the degree of melt and refreezing at the ice surface. In practice, this microscopic variable cannot be measured (Feng and others, 2002). The parameter $\psi$ is the dimensionless rate of isotopic exchange and is given by,

$$
\begin{gathered}
\psi=\frac{k_{r} Z}{u^{*}}, \\
a=\phi\left(1-S_{\mathrm{i}}\right)(S+\beta) \rho_{\mathrm{liq}}, \\
b=\phi\left(1-S_{\mathrm{i}}\right) \rho_{\mathrm{ice}},
\end{gathered}
$$

where $k_{\mathrm{r}}$ is the isotopic exchange rate constant (with the dimension of time $\left.e^{-1}\right), Z$ is the initial ice column depth and $u^{*}$ is the infiltration velocity. The two parameters $(\gamma$ and $\psi$ ) were determined by fitting the model to the experimental data; we then calculated the isotopic exchange rate constant $\left(k_{\mathrm{r}}\right)$ using Eqn (4). Both the two parameters are calculated by water saturation $(S)$, which is assumed constant at constant melt rate. Water saturation is defined as $S=\left(S_{\mathrm{w}}-S_{\mathrm{i}}\right) /\left(1-S_{\mathrm{i}}\right)$, where $S_{\mathrm{w}}$ is the total water volume over the pore volume and $S_{\mathrm{i}}$ is the irreducible water content $\left(S_{\mathrm{i}}=0.04\right.$, Jordan, 1991). Using these values and the height of the ice column (see Eqn 4), the rate constant $k_{\mathrm{r}}$ was calculated as Hibberd (1984) suggested,

$$
u^{*}=\frac{Q}{\phi\left(1-S_{\mathrm{i}}\right)(S+\beta)} \text {. }
$$

The pore volume was calculated from the column porosity, which was calculated using the measured initial bulk density by 


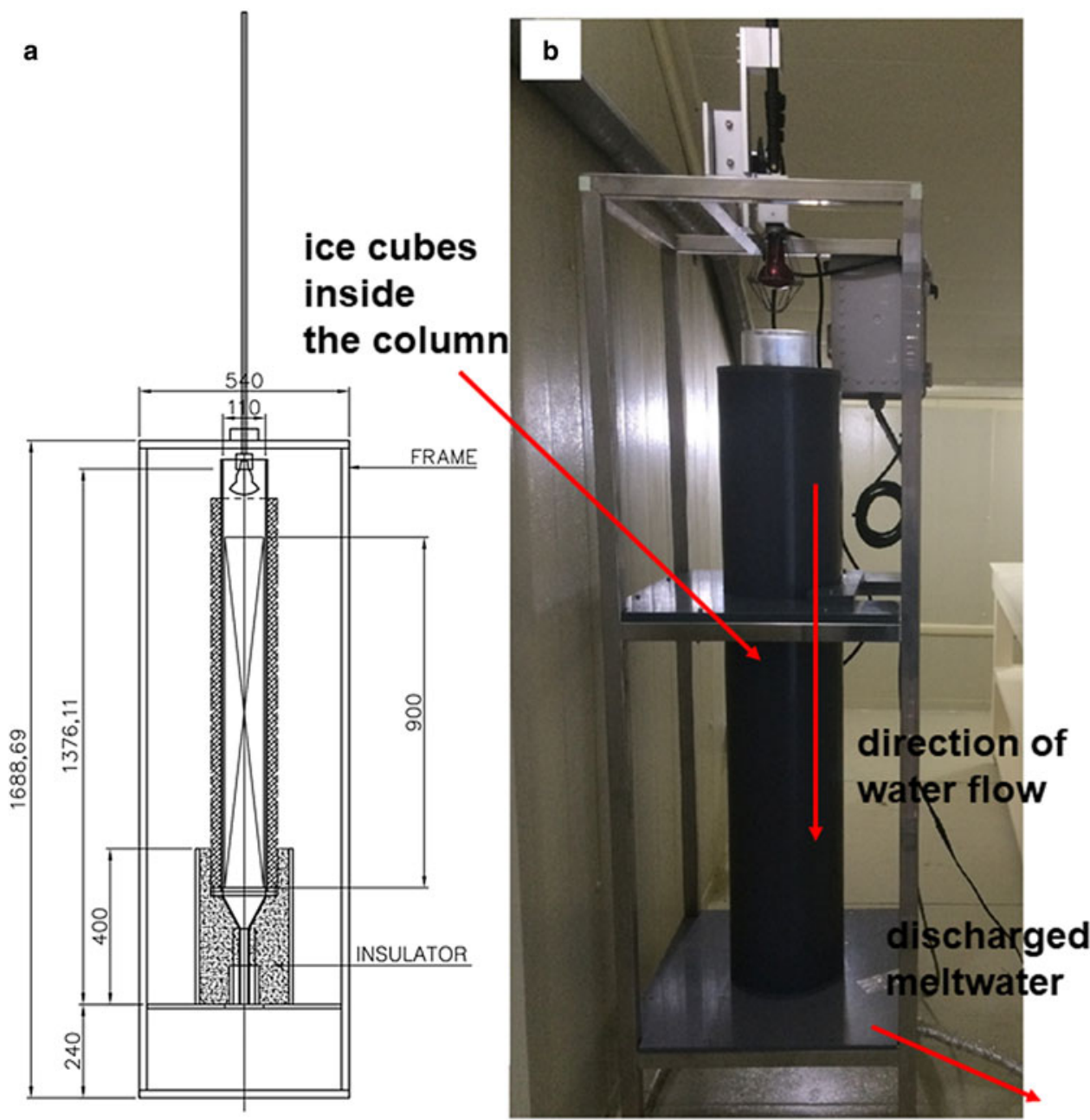

Fig. 1. (a) A schematic diagram of melting experiment, (b) a photo of melting experiment installed. Numbers are expressed in mm.

the following equation (Feng and others, 2002):

$$
\rho_{\text {bulk }}=\phi S_{\mathrm{i}} \rho_{\text {liq }}+(1-\phi) \rho_{\text {ice }} .
$$

We used the oxygen and hydrogen isotopic compositions of the original ice as the initial isotopic composition of both the ice and the irreducible water for model calculations. For each experiment, we calculated the values of $\psi$ and $f$ for the best fit that minimize the sum of squares of the differences between the modeled and analyzed isotopic compositions of the meltwater.

\section{Results}

The four ice-melt experiments were carried out with the column heights of $37.5,37.5,38.5$ and $18.5 \mathrm{~cm}$, respectively. The corresponding durations of each experiment (the time required for the entire column to melt) were $13.05,19.67,26.72$ and $25.13 \mathrm{~h}$, respectively. The values for the bulk density of the ice inside the column (the weight of the ice used in the experiment divided by the volume of the column) for the four experiments were 0.56 , $0.56,0.55$ and $0.57 \mathrm{~g} \mathrm{~cm}^{-3}$, respectively, and the weighted mean specific discharge values (bin size, $0.2 \mathrm{~cm} \mathrm{~h}^{-1}$ ) were $1.96,1.40$, 1.01 and $0.48 \mathrm{~cm} \mathrm{~h}^{-1}$, respectively (see Table 1 and Fig. 2) and the times required to obtain the first meltwater sample were 90 , 190, 245 and $373 \mathrm{~min}$, respectively.

To parameterize the 1-D model, it is necessary to obtain a good estimate of the flow discharge. We estimated this value
Table 1. Summary of the cryosphere laboratory experiments

\begin{tabular}{|c|c|c|c|c|}
\hline & Exp. 1 & Exp. 2 & Exp. 3 & Exp. 4 \\
\hline $\begin{array}{l}\text { Distance between } \\
\text { ice and lamp }(\mathrm{cm})\end{array}$ & 10 & 20 & 10 & 20 \\
\hline $\begin{array}{l}\text { Weight of } \\
\text { ice }(\mathrm{kg})\end{array}$ & 2 & 2 & 2 & 1 \\
\hline Ice height $(\mathrm{cm})$ & 37.5 & 37.5 & 38.5 & 18.5 \\
\hline Watts of lamp & 75 & 75 & 50 & 50 \\
\hline Lamp-ice distance $(\mathrm{cm})$ & 10 & 20 & 10 & 20 \\
\hline $\begin{array}{l}\text { Bulk density } \\
\left(\mathrm{g} \mathrm{cm}^{-3}\right)\end{array}$ & 0.56 & 0.56 & 0.55 & 0.57 \\
\hline $\begin{array}{l}\text { Specific discharge }\left(\mathrm{cm} \mathrm{h}^{-1}\right) \text {, } \\
\text { (weighted mean value) }\end{array}$ & $\begin{array}{l}1.86 \pm 0.43 \\
(1.96)\end{array}$ & $\begin{array}{l}1.30 \pm 0.27 \\
(1.40)\end{array}$ & $\begin{array}{l}0.99 \pm 0.16 \\
(1.01)\end{array}$ & $\begin{array}{l}0.46 \pm 0.17 \\
(0.48)\end{array}$ \\
\hline $\begin{array}{l}\text { Time to first meltwater } \\
\text { sample (min) }\end{array}$ & 90 & 190 & 245 & 373 \\
\hline $\begin{array}{l}\text { Duration of the } \\
\text { experiment (min) }\end{array}$ & 783 & 1180 & 1603 & 1508 \\
\hline
\end{tabular}

from the data measured by the fraction collector that is plotted as the specific discharge (water equivalent depth per unit time, see Fig. 2). For experiment $1,58 \%$ of the meltwater had a specific discharge rate between 1.8 and $2.2 \mathrm{~cm} \mathrm{~h}^{-1}, 79 \%$ of the meltwater had a specific discharge rate between 1.2 and $1.6 \mathrm{~cm} \mathrm{~h}^{-1}$ for experiment $2,69 \%$ of the meltwater had a specific discharge rate between 0.9 and $1.2 \mathrm{~cm} \mathrm{~h}^{-1}$ for experiment 3 and $79 \%$ of the meltwater had a specific discharge rate between 0.4 and $0.65 \mathrm{~cm} \mathrm{~h}^{-1}$ for experiment 4. The weighted mean values of 

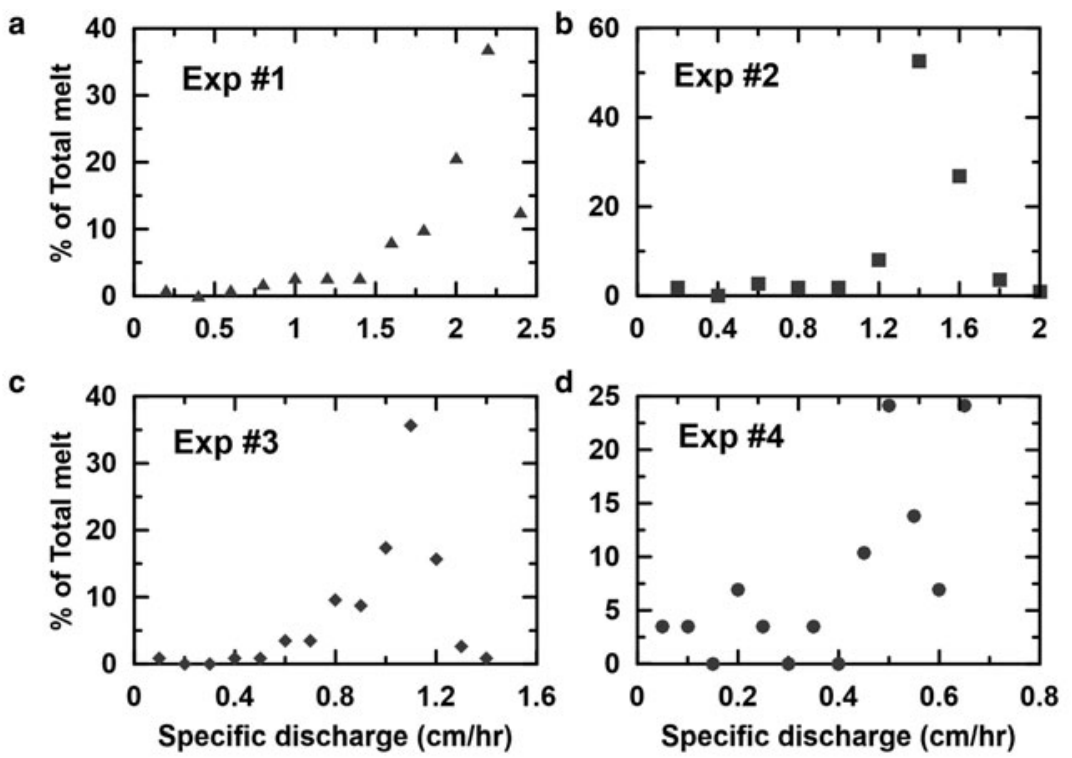

Fig. 2. (a)-(d) Probability density distributions for specific discharge with various melt rates. The percentage of total melt at equally spaced specific discharge intervals was plotted for experiments 1-4. (e) Variations of specific discharge as a function of fraction melted $(F)$.

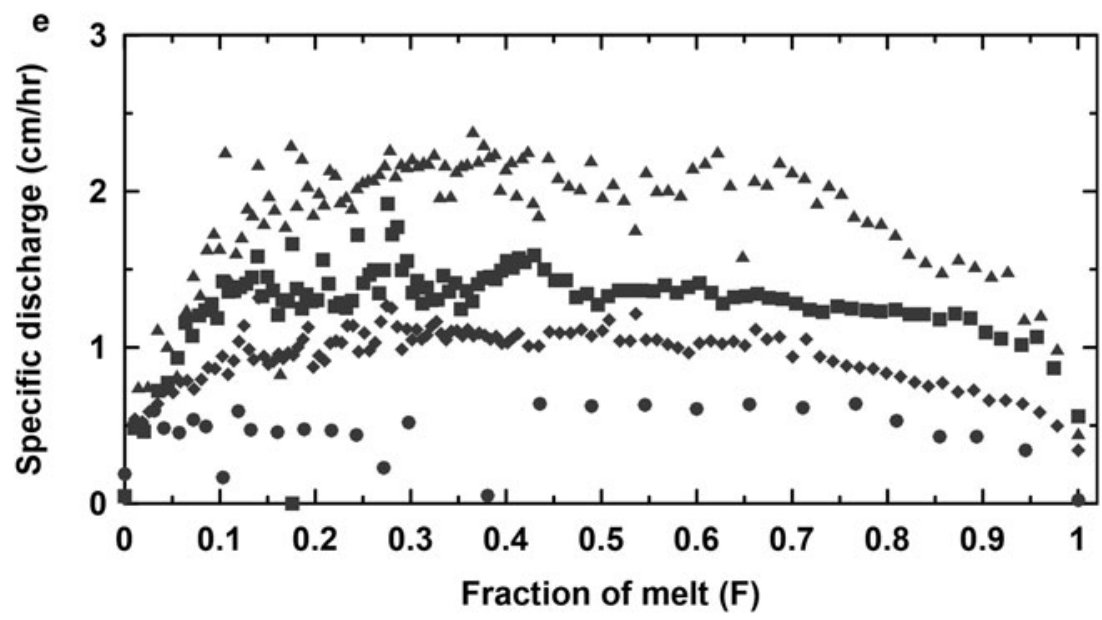

$1.96,1.40,1.01$ and $0.48 \mathrm{~cm} \mathrm{~h}^{-1}$ were used as the model flow rates for experiments $1,2,3$ and 4 , respectively.

The oxygen and hydrogen isotopic compositions of the meltwater are illustrated as a function of the cumulative melt volume divided by the total melt volume $(F)$ measured at the bottom of the melt apparatus (Fig. 3). The isotopic values were scaled for plotting as the relative isotopic difference between each sample and the initial ice by subtracting the average initial isotopic compositions of the ice from all of the analyzed values.

All of the performed measurements and simulations showed that the $\delta^{18} \mathrm{O}$ and $\delta \mathrm{D}$ values for the first $5 \%$ of melt decrease and then increased until the end of each experiment. The isotopic decrease for the first $5 \%$ of the melt can be explained by the fact that the initial pore water is isotopically similar to the bulk ice (Feng and others, 2002; Taylor and others, 2002; Lee and others, 2010a). We also simulate the trend by assuming the isotopic composition of the initial pore water equal to that of the bulk ice. The isotopic depletion values for experiments $1-4$ were $0.8,1.4,1.5$ and $1.0 \%$ and $5.1,10.0,7.7$ and $6.4 \%$ for $\delta^{18} \mathrm{O}$ and $\delta \mathrm{D}$, respectively. The isotopic increase after the first $5 \%$ of the melt follows a non-linear trend for experiment 2 , but linear trends were observed for experiments 1,3 and 4 .

To obtain the isotopic compositions of meltwater from ice, Eqns (1) and (2) were solved simultaneously for the parameters $\gamma$ and $\psi$. In each experiment, a significant fraction of the ice column was melted before the meltwater first appeared at the base of the column and the discharge was relatively constant from this time until the end of the experiment. At the time of the first meltwater appearance, the meltwater must have been held in the unmelted area of the ice column as pore water. We calculated the effective water content, $S$, by assuming this meltwater is evenly distributed. The mass of ice $(b)$ and water $(a)$ is linked with the effective water content in Eqns (5) and (6).

As shown in Figure 3, the model results fit the data reasonably well. The optimized parameters for each calculation are listed in Table 2. The best fit values of $\psi$ of the oxygen isotopes are 0.34 , $1.12,0.57$ and 0.34 and $0.46,1.19,0.45$ and 0.35 of hydrogen isotopes for experiments $1,2,3$ and 4 , respectively. The calculated oxygen $k_{\mathrm{r}}$ values were $0.30,0.77,0.29$ and $0.21 \mathrm{~h}^{-1}$ and the hydrogen $k_{\mathrm{r}}$ values were $0.41,0.82,0.21$ and $0.22 \mathrm{~h}^{-1}$ for experiments 1,2 , 3 and 4, respectively (see Eqn 4 and 7). The best fit $f$ values for the oxygen isotope were $0.275,0.100,0.550$ and 0.525 and those for the hydrogen isotopes were $0.200,0.150,0.325$ and 0.575 for experiments $1,2,3$ and 4 , respectively.

\section{Discussion}

\subsection{Isotopic modification by melt process}

Mass-balance calculations show that $98.8,99.0,99.6$ and $95.0 \%$ of the meltwater was retrieved from experiments $1,2,3$ and 4 , respectively. During the experiments, there may be some 

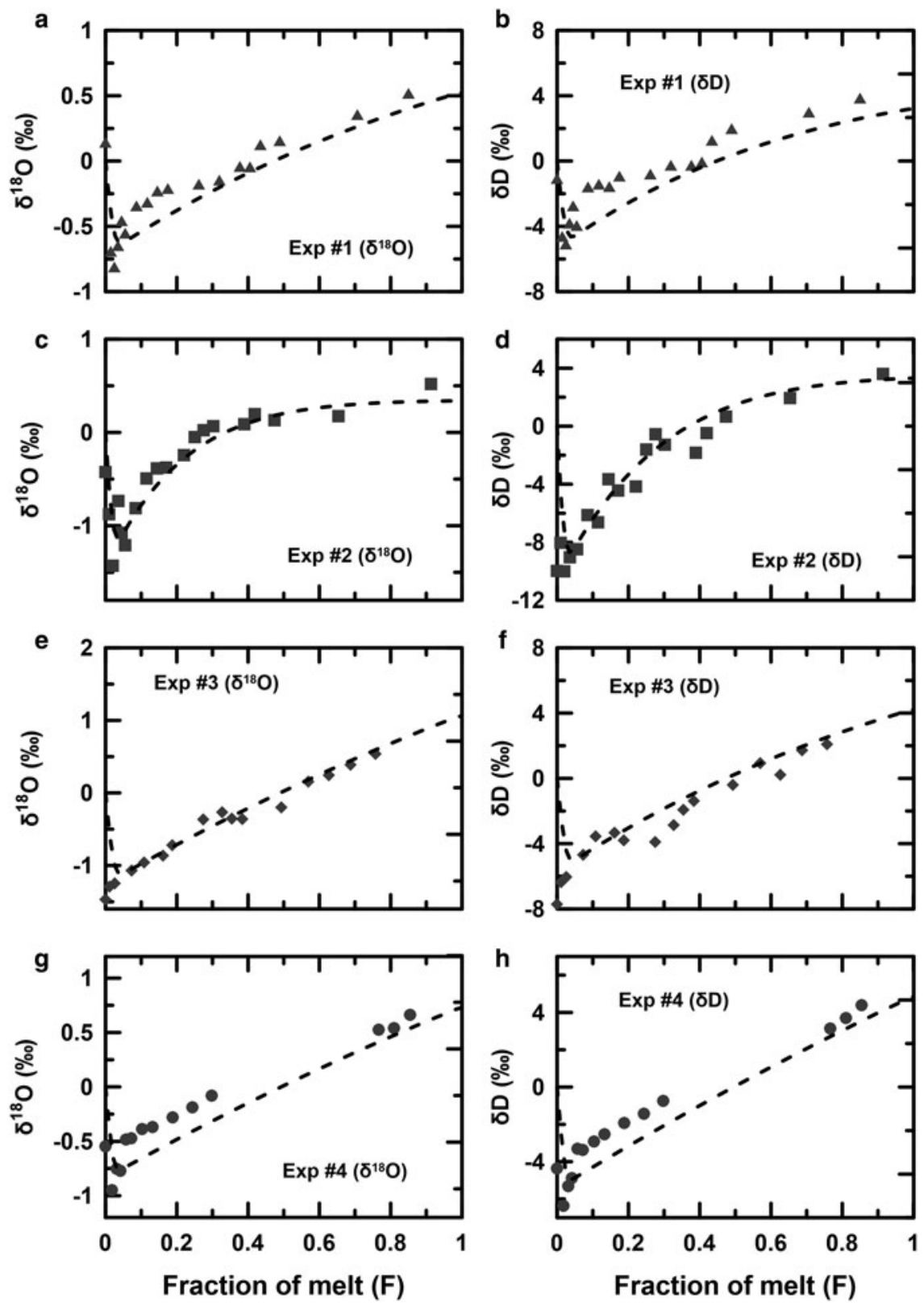

Fig. 3. Isotopic compositions of ice-melt (points) and model results (dashed line) plotted vs $F$, the fraction of ice melted: (a) and (b) experiment 1, (c) and (d) experiment 2, (e) and (f) experiment 3 and $(\mathrm{g})$ and $(\mathrm{h})$ experiment 4 .

evaporation or sublimation, giving rise to the loss of water $(<5 \%)$. These mass losses are within the range found by Herrmann and others (1981) $(4 \sim 13 \%)$ and Taylor and others (2002) $(4 \sim 8 \%)$ in snow experiments. An enrichment in isotopic values compared to the original ice (see Table 2) suggests evaporation or sublimation (Sokratov and Golubev, 2009). Since we did not analyze the whole samples of meltwater, the isotopic mass balance is more difficult to constrain. We interpolated the values for the unanalyzed samples from the $\delta^{18} \mathrm{O}$ and $\delta \mathrm{D}$ values of the similar samples. Except for experiment 3, the volume-weighted average $\delta^{18} \mathrm{O}$ and $\delta \mathrm{D}$ values of the meltwater from the experiments compared to the isotopic compositions of original ice were less than the experimental precision by 0.02 and $0.60 \%$ o for experiment 1 , by -0.01 and $-0.72 \%$ for experiment 2 , by -0.25 and $-1.32 \%$ for experiment 3 and by 0.04 and $0.09 \%$ for experiment 4 respectively. Therefore, isotopic change caused by evaporation or sublimation can be ignored in the subsequent discussion.

Investigation of the slope of the $\delta^{18} \mathrm{O}$ vs $\delta \mathrm{D}$ regression line is a widely used technique in isotope hydrology (Clark and Fritz, 1997; Earman and others, 2006; Lee and others, 2010a; Bush and others, 2017). This slope from the regression line provides information about whether water has experienced significant evaporation, sublimation and isotopic exchange between liquid water, ice and water vapor (Earman and others, 2006; Zhou and others, 2008a, 2008b; Lee and others, 2009; Sokratov and Golubev, 2009; Lee, 2014). Since the isotopic fractionation between liquid water and ice is 3.1 and $19.5 \%$ for oxygen and hydrogen, respectively, Zhou and others (2008a) and Lee and others (2010a) stated that the slope of $\delta^{18} \mathrm{O}$ vs $\delta \mathrm{D}$ of meltwater should be different from that of the meteoric waterline (MWL) of 8. Theoretically, the slope should be close to 19.5/3.1 6.3 (ratio of hydrogen and oxygen isotopic fractionation between ice and liquid water).

The $\delta^{18} \mathrm{O}-\delta \mathrm{D}$ plots obtained in this work are shown in Figure 4 . The slopes of the $\delta \mathrm{D}-\delta^{18} \mathrm{O}$ plots for experiments $1-4$ are $6.6_{4}, 6.8_{4}, 4.3_{6}$ and $6.8_{5}$, respectively. The slopes of the $\delta \mathrm{D}-\delta^{18} \mathrm{O}$ plots for the model for experiments $1-4$ are $6.8_{0}, 8.3_{2}$, $4.1_{5}$ and $6.6_{1}$, respectively. This result suggests that a slope of significantly $<8$ can be obtained without considering the sublimation process (Earman and others, 2006; Lee and others, 2009). Near the surface, snow or ice exchanges with atmospheric water vapor and this exchange modify the linear relationship to 88.2/ 
Table 2. Model parameters used and obtained from the column experiments

\begin{tabular}{|c|c|c|c|c|c|c|}
\hline Parameter & Units & Exp. 1 & Exp. 2 & Exp. 3 & Exp. 4 & Source \\
\hline $\begin{array}{l}\text { Bulk density (column volume/ } \\
\text { weight of ice cubes used) }\end{array}$ & $\mathrm{g} \mathrm{cm}^{-3}$ & 0.56 & 0.56 & 0.55 & 0.57 & Measured \\
\hline Icepack height $Z$ & $\mathrm{~cm}$ & 37.5 & 37.5 & 38.5 & 18.5 & Measured \\
\hline Specific discharge $Q$ & $\mathrm{~cm} \mathrm{~h}^{-1}$ & 1.96 & 1.40 & 1.01 & 0.48 & Measured \\
\hline Porosity $\Phi$ & & 0.38 & 0.38 & 0.39 & 0.37 & Calculated \\
\hline Irreducible water content $S_{\mathrm{i}}$ & & 0.04 & 0.04 & 0.04 & 0.04 & Jordan (1991) \\
\hline Water saturation $S$ & & 0.120 & 0.107 & 0.096 & 0.075 & \\
\hline Percolation velocity $u^{\star}$ & $\mathrm{cm} \mathrm{h}^{-1}$ & 33.47 & 25.95 & 19.39 & 11.61 & \\
\hline Intrinsic permeability $k$ & $\mathrm{~m}^{2}$ & $5.72 \times 10^{-10}$ & $5.72 \times 10^{-10}$ & $5.72 \times 10^{-10}$ & $5.72 \times 10^{-10}$ & \\
\hline Hydraulic conductivity $K$ & $\mathrm{~cm} \mathrm{~h}^{-1}$ & $3.12 \times 10^{-3}$ & $3.12 \times 10^{-3}$ & $3.12 \times 10^{-3}$ & $3.12 \times 10^{-3}$ & Morris and Johnson (1967) \\
\hline Initial $\delta^{18} \mathrm{O}$ and $\delta \mathrm{D}$ & $\%$ & $-8.42,-61.26$ & $-8.68,-58.33$ & $-8.37,-60.10$ & $-9.22,-64.12$ & Measured \\
\hline$\alpha\left(\delta^{18} \mathrm{O}\right.$ and $\left.\delta \mathrm{D}\right)$ & & $1.0031,1.0195$ & $1.0031,1.0195$ & $1.0031,1.0195$ & $1.0031,1.0195$ & O’Neil (1968) \\
\hline$f\left(\delta^{18} \mathrm{O}\right.$ and $\left.\delta \mathrm{D}\right)$ & & $0.275,0.200$ & $0.100,0.150$ & $0.550,0.325$ & $0.525,0.575$ & Optimized \\
\hline$\gamma\left(\delta^{18} \mathrm{O}\right.$ and $\left.\delta \mathrm{D}\right)$ & & $0.8814,0.6573$ & $0.5100,0.6455$ & $0.5122,0.9018$ & $0.9089,0.9213$ & \\
\hline$A$ & & 0.0585 & 0.0539 & 0.0521 & 0.0413 & \\
\hline$B$ & & 0.5612 & 0.5612 & 0.5466 & 0.5688 & \\
\hline$\Psi\left(\delta^{18} \mathrm{O}\right.$ and $\left.\delta \mathrm{D}\right)$ & & $0.34,0.46$ & $1.12,1.19$ & $0.57,0.42$ & $0.34,0.35$ & Optimized \\
\hline$k_{\mathrm{r}}\left(\delta^{18} \mathrm{O}\right.$ and $\left.\delta \mathrm{D}\right)$ & $\mathrm{h}^{-1}$ & $0.30,0.41$ & $0.77,0.82$ & $0.29,0.21$ & $0.21,0.22$ & This work \\
\hline
\end{tabular}

$11.4 \sim 7.7$ (Earman and others, 2006). Sokratov and Golubev (2009) found that the isotopic compositions of snow became more enriched by sublimation and the ratio between the two water isotopes deviated from the MWL. Zhou and others (2008a) investigated the isotopic compositions of pore water and snowpack using two water isotopes and reported that the slope of the liquid phase was lower than that of the solid phase. Then the refreezing process would cause the slope of the solid phase to decrease because of the discrepancy between the slopes of the two phases, snow and liquid water.

When meltwater infiltrates through ice, isotopic exchange occurs between liquid water and ice, giving rise to isotopic redistribution in ice (Lee and others, 2010b; Dahlke and Lyon, 2013). Only a few studies have investigated how snow, firn and ice change isotopically by water or vapor flow (Stichler and others, 2001; Moran and Marshall, 2009; Moran and others, 2011). Moran and Marshall (2009) discussed the processes that affect the isotopic compositions of liquid and solid phases in open and closed systems. In open systems, in particular, the exchange of the mass with the surrounding environment results in the enrichment of the solid phases because the light isotopes are preferentially removed from the systems via sublimation and melt processes. They also concluded that the overestimation of the annual temperature from stable isotopes is likely to result from the ice cores experiencing moderate to high melts. The good fit obtained with the model parameterized in the present work indicates that our model captures the physical processes that control the isotopic compositions of meltwater. In addition, constraining the value of $k_{\mathrm{r}}$ is critical when this model is extended to field conditions.

\subsection{Parameters depending on hydrological conditions}

The range of isotopic exchange rate constant $\left(k_{\mathrm{r}}\right)$ values, from 0.21 (experiment 4 of oxygen) to 0.82 (experiment 2 for hydrogen), is much larger than that obtained by Taylor and others (2002) and Lee and others (2010a) from snowmelt, where the range was reported to be from 0.07 to $0.20 \mathrm{~h}^{-1}$. To examine whether the ranges of the $k_{\mathrm{r}}$ and $f$ values are statistically different between the two isotopes, we present the calculated 95\% confidence regions based on the sum of squares errors in the $k_{\mathrm{r}}-f$ plane for each of the calculations in Figure 5 (Seber and Wild, 1989; Feng and Savin, 1993; Lee and others, 2009). As noted by Lee and others (2009), the isotopic exchange rate constant, $k_{\mathrm{r}}$ and the fraction of ice involved in the isotopic exchange, $f$, may differ from one column to another, depending on the melt conditions. All confidence regions exhibit a diagonal shape, indicating that the best fit of $k_{\mathrm{r}}$ is fairly correlated with the best fit of $f$.

Next, we examine the confidence regions to determine whether or not the rates of oxygen and hydrogen isotopic exchange between liquid water and ice are significantly different. When the confidence regions overlap, such as in experiments 1,2 and 4 , the $k_{\mathrm{r}}$ and $f$ values estimated from each of the two simulations are not significantly different, even though the best fit $k_{\mathrm{r}}$ values for hydrogen greater than those for oxygen (see Table 1 and Fig. 5). For experiment 3, although the confidence regions do not overlap, the individual values of $k_{\mathrm{r}}$ and $f$ do overlap. If one argues that the $f$ values should not differ for oxygen and hydrogen isotopic results (because they are obtained from the same experiment), then the $k_{\mathrm{r}}$ value for hydrogen isotopic exchange would be significantly greater by $28 \%$ ( 0.29 for hydrogen vs 0.21 for oxygen). It still remains inconclusive whether the two exchange rate constants are the same or different under a wide range of flow conditions, but a $28 \%$ difference in this parameter may not be physically significant.

Isotopic exchange is correlated with the surface area of the contact between liquid water and ice and the rate of melt and recrystallization that are associated with the moisture inside the ice. Compared to the effective saturation in ice, the $f$ values decrease with increasing moisture content, which is not consistent with what Lee and others (2009) found (Fig. 6a). Lee and others (2009) argued that isotopic exchange between liquid water and ice increases with increasing wetness. When the wetness increases, the isotopic exchange between liquid water and ice increases due to the increasing surface area of contact and recrystallization. However, in this experiment, water flows through the ice with a high velocity when the melt rate is relatively high, limiting the time of contact between liquid water and ice and thus the fraction of ice involved in the isotopic exchange decreases with increasing wetness in ice. The surface area available for the direct interaction between liquid water and ice is reduced when the water content increases. This is reasonable because there may be water only in the small pores or bypass some of the water that has exchanged with ice, which decreases the effective surface area over which the isotopic exchange can occur.

Figure $6 \mathrm{~b}$ illustrates the relationship between the isotopic exchange rate constant and the pore water velocity that is closely correlated with the effective water saturation (see Fig. 6c). The isotopic exchange rate constant $\left(k_{\mathrm{r}}\right)$ increases exponentially with the mean 

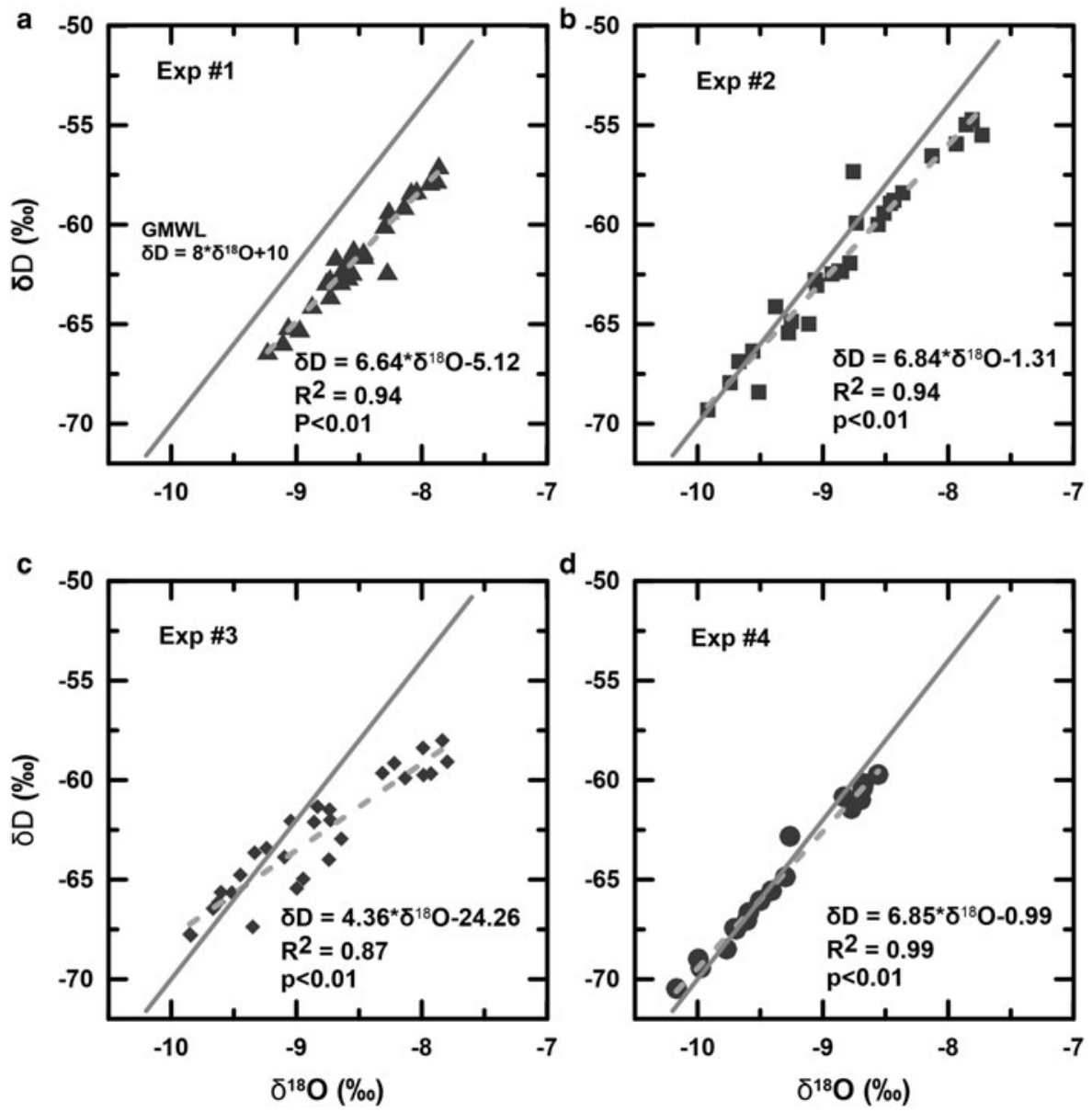

Fig. 4. $\delta \mathrm{D}$ vs $\delta^{18} \mathrm{O}$ plots for four melt experiments. The gray solid line indicates the global meteoric waterline (GMWL) in each figure. All of the $\delta \mathrm{D}$ vs $\delta^{18} \mathrm{O}$ slopes of

a
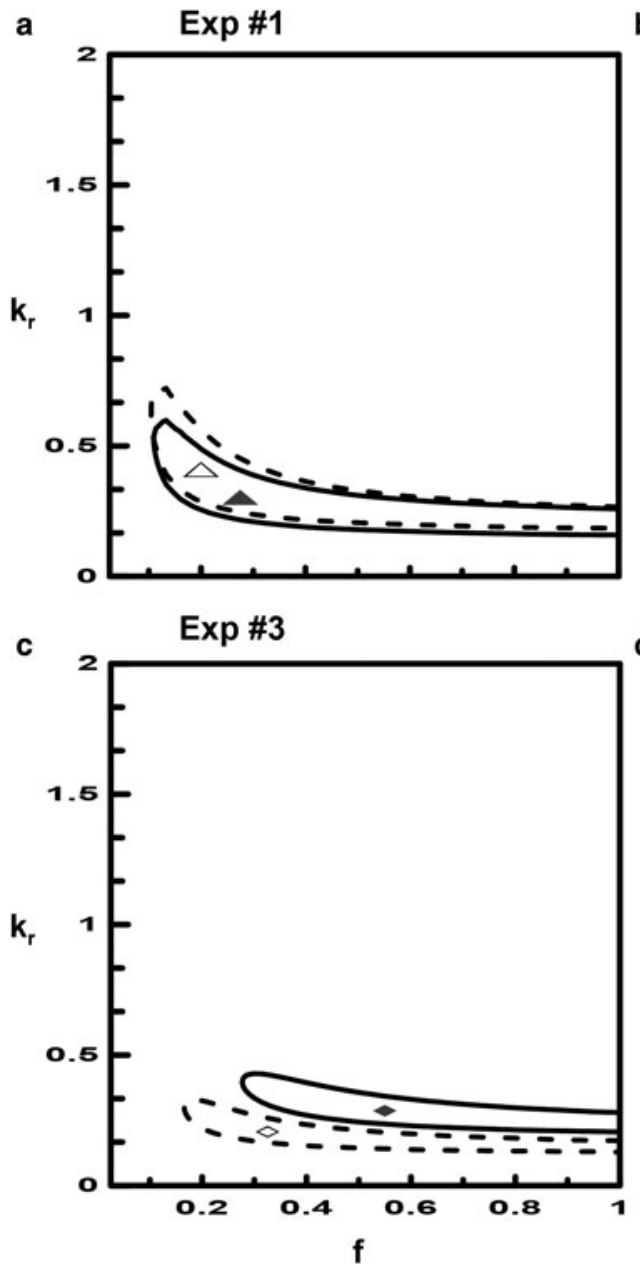
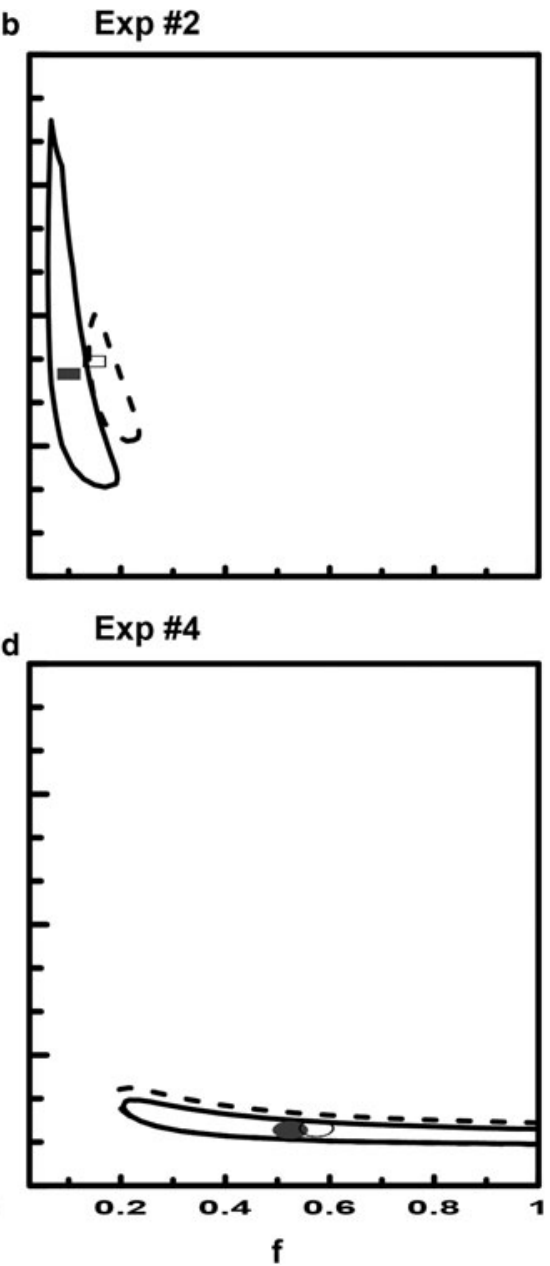

Fig. 5. Confidence regions (95\%) for the estimates of parameters $k_{r}$ and $f$ from oxygen and hydrogen isotopic measurements. In each panel, closed and open symbols represent the best fit for oxygen and hydrogen, respectively. 

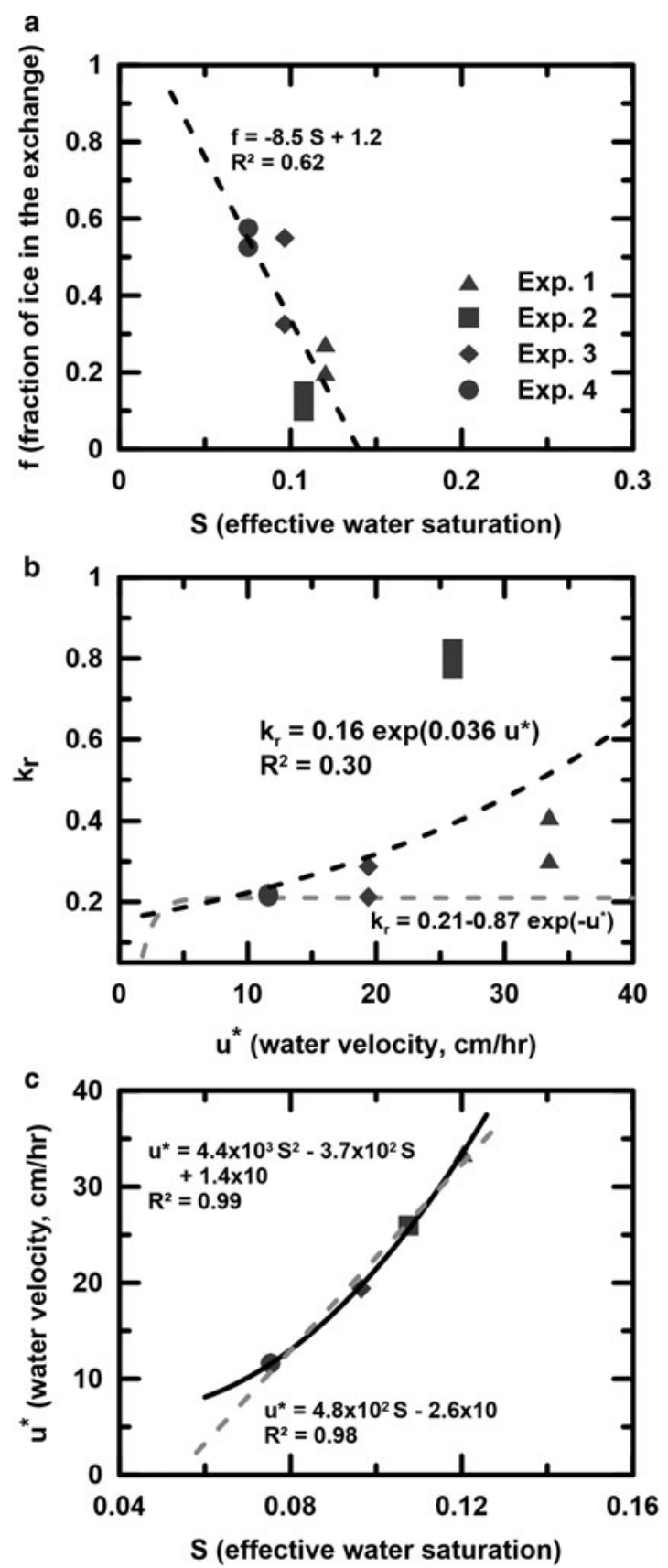

Fig. 6. (a) Effective water saturation $(S)$ vs fraction of ice in the liquid water-ice isotopic exchange system $(f)$. (b) Isotopic exchange rate constant $\left(k_{r}\right)$ vs pore water velocity $\left(u^{\star}\right)$. Gray dashed lines are presented as in Lee and others (2009) for comparison. (c) Effective water saturation $(S)$ vs pore water velocity $\left(u^{\star}\right)$ by linear (gray) and quadratic (black) function.

water velocity $\left(u^{*}\right)$. What causes the dependency of $k_{\mathrm{r}}$ on pore water velocity is not clear, but it can be explained that the water bypasses some of the water that has exchanged with the ice and thus not all of the isotopically exchanged water appears in the discharge (Fig. 6a), which the model does not consider. The model, thus, results in a lower-best fit exchange rate constant than during a higher flow. Therefore, the variable $k_{\mathrm{r}}$ may be an outcome of model assumption that does not apply to the actual flow in the ice.

\section{Conclusion}

The rate constants for isotopic exchange between liquid water and ice were examined using four melt experiments and a physically based 1-D model. We found that the rate constant for the hydrogen isotopic exchange between liquid water and ice may be greater than that for oxygen isotopic exchange (up to 40\%). The range of the rate constant obtained from four melt experiments range from 0.21 to $0.82 \mathrm{~h}^{-1}$. The model results also suggest that $f$, the fraction of ice involved in the isotopic exchange, decreases with increasing wetness of ice. This is because with increasing water saturation in ice, there may be water only in the small pores or bypass some of the water that has exchanged with ice, which decreases the effective surface area over which isotopic exchange can occur.

The observation and simulation results yielded $\delta \mathrm{D}-\delta^{18} \mathrm{O}$ slopes of $<8$ and close to the theoretical value of 6.3. This slope is similar to the ratio of hydrogen and oxygen isotopic fractionation between ice and liquid water and different from the slope of the MWL. We note that these slopes were obtained from the laboratory experiments and model calculations without considering the sublimation process.

Meltwater influences on snow and ice need to be further examined and quantified to better constrain potentially large impact on isotope thermometry. Percolation of water during warm events will tend to diffuse downward and advect the isotopic signal in the snow/ice strata, which smooths the isotopic variations in the record of isotopes vs depth. Our work may help in controlling the magnitude of the possible consequences of these processes and in evaluating the accuracy of isotopes in ice cores as a proxy for temperature.

Acknowledgements. This work was financially supported by KOPRI research grants (PE19040 and KIMST20190361). We appreciate the scientific editor and two anonymous reviewers, whose comments led to significant improvements.

\section{References}

Bush RT, Berke MA and Jacobson AD (2017) Plant water D and ${ }^{18} \mathrm{O}$ of tundra species from west Greenland. Arctic, Antarctic, and Alpine Research 49, 341-358. doi: 10.1657/AAAR0016-025.

Clark I and Fritz P (1997) Environmental Isotopes in Hydrogeology. Lewis, Boca Raton, FL

Dahlke HE and Lyon SW (2013) Early melt season snowpack isotopic evolution in the Tarfala valley, northern Sweden. Annals of Glaciology 54(62), 149-156. doi: 10.3189/2013AoG62A232.

Earman S, Campbell AR, Phillips FM and Newman BD (2006) Isotopic exchange between snow and atmospheric water vapor: estimation of the snowmelt component of groundwater recharge in the southwestern United States. Journal of Geophysical Research 111, D09302. doi: 10.1029/ 2005JD006470.

Feng X and Savin SM (1993) Oxygen isotope studies of zeolites-stilbite, analcime, heu-landite, and clinoptilolite: II. Kinetics and mechanisms of isotopic exchange between zeolites and water vapor. Geochim. Cosmochim. Acta 57, 4219-4238.

Feng X, Taylor S, Renshaw CE and Kirchner JW (2002) Isotopic evolution of snowmelt. 1. A physically based one-dimensional model. Water Resources Research 38(10), 1217. doi: 10.1029/2001WR000814.

Goto-Azuma K, Koerner RM and Fisher DA (2002) An ice-core record over the last two centuries from Penny Ice Cap, Baffin Island, Canada. Annals of Glaciology 35, 29-35. doi: 10.3189/172756402781817284.

Herrmann A, Lehrer M and Stichler W (1981) Isotope input into runoff systems from melting snow covers. Nord. Hydrol 12(4-5), 309-318.

Hibberd S (1984) A model for pollutant concentration during snow-melt. Journal of Glaciology 30(104), 58-65. doi: 10.3189/S0022143000008492.

Hou S and 6 others (2013) A new Himalayan ice core $\mathrm{CH}_{4}$ record: possible hints at the preindustrial latitudinal gradient. Climate of the Past 9, 25492554. doi: 10.5194/cp-9-2549-2013.

Jordan RE (1991) A one-dimensional temperature model for a snow cover. Spec. Rep., 91-16, Cold Regions Res. and Eng. Lab., Hanover, NH.

Kaczmarska $\mathbf{M}$ and 8 others (2006) Ice core melt features in relation to Antarctic coastal climate. Antarct. Sci. 18, 271-278. 
Koerner RM (1997) Some comments on climatic reconstruction from ice cores drilled in areas of high melt. Journal of Glaciology 43(143), 90-97. doi: $10.3189 / \mathrm{S} 0022143000002847$.

Lee $\mathbf{J}$ and 5 others (2008a) Modeling of solute transport in snow using conservative tracers and artificial rain-on-snow experiments. Water Resources Research 44, W02411. doi: 10.1029/2006WR005477.

Lee $\mathbf{J}$ and 5 others (2008b) A study of solute redistribution and transport in seasonal snowpack using natural and artificial tracers. Journal of Hydrology 357, 243-254. doi: 10.1016/j.jhydrol.2008.05.004.

Lee $\mathbf{J}$ and 6 others (2010a) Isotopic evolution of a seasonal snowcover and its melt by isotopic exchange between liquid water and ice. Chemical Geology 270, 126-134. doi: 10.1016/j.chemgeo.2009.11.011.

Lee $\mathbf{J}$ and 5 others (2010b) Isotopic evolution of snowmelt: a new model incorporating mobile and immobile water. Water Resources Research 46, W11512. doi: 10.1029/2009WR008306.

Lee J (2014) A numerical study of isotopic evolution of a seasonal snowpack and its meltwater by total rates. Geosciences Journal 18, 503-510. doi: 10 . 1007/s12303-014-0019-5.

Lee $\mathrm{K}$ and 5 others (2015b) Seasonal variation in the input of atmospheric selenium to northwestern Greenland snow. Science of the Total Environment 526, 49-57. doi: 10.1016/j.scitotenv.2015.04.082.

Lee J, Feng X, Posmentier ES, Faiia AM and Taylor S (2009) Stable isotopic exchange rate constant between snow and liquid water. Chemical Geology 260, 57-62. doi: 10.1016/j.chemgeo.2008.11.023.

Lee J, Han Y, Ham JY and Na US (2015a) A study of stable isotopic variations of Antarctic snow by albedo differences. Polar and Ocean Research 37, 141147. doi: 10.4217/OPR.2015.37.2.141.

Masson-Delmotte V and 35 others (2008) A review of Antarctic surface snow isotopic compositions: observations, atmospheric circulation, and isotopic modeling. Journal of Climate 21, 3359-3387. doi: 10.1175/2007JCLI2139.1.

Moore JC, Grinsted A, Kekonen T and Pohjola V (2005) Separation of melting and environmental signals in an ice core with seasonal melt. Geophysical Research Letters 32, L10501. doi: 10.1029/2005GL023039.

Moran T and Marshall S (2009) The effects of meltwater percolation on the seasonal isotopic signals in an Arctic snowpack. Journal of Glaciology 55 (194), 1012-1024. doi: 10.3189/002214309790794896.

Moran T, Marshall SJ and Sharp MJ (2011) Isotope thermometry in melt-affected ice cores. Journal of Geophysical Research 116, F02010. doi: 10.1029/2010JF001738
Morris DA and Johnson AI (1967) Summary of hydrologic and physical properties of rock and soil materials, as analyzed by the hydrologic laboratory of the U.S. Geological Survey, 1948-1960. USGS Water Supply Paper: 1839-D.

O'Neil JR (1968) Hydrogen and oxygen isotope fractionation between ice and water. J. Phys. Chem. 72, 3683-3684.

Penna D and 14 others (2012) Technical note: evaluation of between-sample memory effects in the analysis $\delta^{2} \mathrm{H}$ and $\delta^{18} \mathrm{O}$ of water samples measured by laser spectroscopes. Hydrology and Earth System Sciences 16, 3925-3933. doi: 10.5194/hess-16-3925-2012.

Pohjola VA and 7 others (2002) Effect of periodic melting on geochemical and isotopic signals in an ice core from Lomonosovfonna, Svalbard. Journal of Geophysical Research 107(D4), 4036. doi: 10.1029/2000JD000149.

Seber GA and Wild CJ (1989) Nonlinear Regression. Wiley, NJ.

Sokratov S and Golubev VN (2009) Snow isotopic content change by sublimation. Journal of Glaciology 55(193), 823-828. doi: 10.3189/ 002214309790152456.

Steen-Larsen HC and 23 others (2011) Understanding the climatic signal in the water stable isotope records from the NEEM shallow firn/ice cores in northwest Greenland. Journal of Geophysical Research 116, D0618. doi: 10.1029/2010JD014311.

Stichler W and 6 others (2001) Influence of sublimation on stable isotope records recovered from high-altitude glaciers in the tropical Andes. J. Geophys. Res. 106(D19), 22613-22620.

Taylor S and 5 others (2001) Isotopic evolution of a seasonal snowpack and its melt. Water Resources Research 37(3), 759-769. doi: 10.1029/2000WR900341.

Taylor S, Feng X, Renshaw CE and Kirchner JW (2002) Isotopic evolution of snowmelt. 2. Verification and parameterization of a one-dimensional model using laboratory experiments. Water Resources Research 38(10), 1218. doi: 10.1029/2001WR000815.

Thompson LG and 12 others (1998) A 25000-year tropical climate history from Bolivian ice cores. Science 282, 1858-1864. doi: 10.1126/science.282. 5395.1858.

Zhou S, Nakawo M, Hashimoto S and Sakai A (2008a) The effect of refreezing on the isotopic composition of melting snowpack. Hydrological Processes 22, 873-882. doi: 10.1002/hyp.6662.

Zhou S, Nakawo M, Hashimoto S and Sakai A (2008b) Preferential exchange rate effect of isotopic fractionation in a melting snowpack. Hydrological Processes 22, 3734-3740. doi: 10.1002/hyp.6977. 